\title{
Faktor-Faktor Yang Berhubungan Dengan Kejadian Kecacingan Soil Transmitted Helminths Pada Anak Usia 1 - 5 Tahun Di Rw 07 Geringging Kecamatan Rumbai Pesisir
}

\author{
Sri Kartini ${ }^{1}$, Ilham Kurniati ${ }^{2}$, Nandriya Safarin Jayati ${ }^{3}$, Windra Sumitra ${ }^{4}$ \\ ${ }^{1}$ Program Stidi Analis Farmasi dan Makanan Universitas Abdurrab \\ ${ }^{2-4}$ Akademi Analis Kesehatan Yayasan Fajar \\ 1) email : sri.kartini@univrab.ac.id \\ 2) email : ilham.kurniata@aakfajar.ac.id \\ 3) email :nandriyasafarinjayati@gmail.com \\ 4).email: windrasumirta@gmail.com
}

\begin{abstract}
Helminthiasis is a disease that occurs in the population in the tropics and subtropics area.One of the helminthiasis in humans is Soil Transmitted Helminth (STH). The prevalence of this disease is still to be a concern because the prevalence is quite high in children that is no exception in the children aged 1-5 years. The factors causing helminthiasis are included behavioral and environmental factors. This study aims to determine the factors that are related to STH helminthiasis incidence among others, the habit of washing hand of mothers, the habit of wearing footwear, the cleanliness of mother and child's nails, the availability of clean water, the availability of latrines and the availability of the trash. The sample is the total population of 55 children aged 1-5 years in RW 07 Geringging Rumbai Pesisir District. This research is an observational quantitative with cross sectional design.Data is taken from the result of questionnaire and human fecal sample. The data were analyzed using chi square test. The result of the research showing STH infected children were 7 people $(12,7 \%)$. The types of the worm eggs that infect are Ascaris lumbricoides (7.2\%), Trichuris trichiura (3.6\%), and hookworm (1.8\%). The result of statistical test showed that there was a relationship between hand washing habits $(p=0,039)$, children habit wearing footwear $(\mathrm{p}=0,002)$, clean of mother and child nail $(\mathrm{p}=0,041)$, clean water supply $(\mathrm{p}=$ $0,016)(p=0,024)$ and there is no relation between garbage availability $(p=0,168)$ ) to the occurrence of helminthiasis.
\end{abstract}

Keywords: Helminthiasis, washing hand of mothers, wearing children's footwear, cleaning mother's and children's nails, availability of clean water, availability of latrines

\begin{abstract}
ABSTRAK
Kecacingan merupakan penyakit yang terjadi pada penduduk di daerah tropis dan subtropis, salah satu kecacingan pada manusia yaitu Soil Transmitted Helminth (STH). Prevalensi penyakit ini masih menjadi perhatian karena prevalensinya cukup tinggi pada anak tidak terkecuali pada anak usia 1-5 tahun. Beberapa faktor penyebab kecacingan dianataranya faktor prilaku dan lingkungan. Penelitian ini bertujuan untuk mengetahui faktor-faktor yang hubungan dengan kejadian cacing STH diantaranya ,kebiasaan mencuci tanganibu, kebiasaan memakai alas kaki,kebersihan kuku ibu dan anak, ketersediaan air bersih, ketersediaan jamban dan ketersediaan tempat sampah. Sampel adalah total populasi berjumlah 55 orang anak usia 1-5 tahun di RW 07 Geringging Kecamatan Rumbai Pesisir. Penelitian ini merupakan kuantitatif observasional dengan desain cross sectional.Data diambil dari hasil kuesioner dan sampel feses. Data dianalisis menggunakan uji chi square. Hasil penelitian menunjukkan anak yang terinfeksi STH berjumlah 7 orang $(12,7 \%)$. Jenis telur cacing yang menginfeksi adalah Ascaris lumbricoides (7,2\%), Trichuris trichiura $(3,6 \%)$, dan cacing tambang $(1,8 \%)$. Hasil uji statistik menunjukkan ada hubungan antara kebiasaan ibu mencuci tangan $(p=0,039)$, kebiasaan memakai alas kaki $(p=0,002)$, kebersihan kuku ibu dan anak $(p=0,041)$, ketersediaan air bersih $(p=0,016)$, ketersediaan jamban $(p=0,024)$ dan tidak terdapat hubungan antara ketersediaan tempat sampah $(\mathrm{p}=0,168)$ )terhadap kejadian kecacingan
\end{abstract}

Kata Kunci: Kecacingan, mencuci tangan ibu dan anak, memakai alas kaki, kebersihan kuku ibu dan anak, ketersediaan air bersih,ketersediaan jamban 


\section{Pendahuluan}

Penyakit kecacingan merupakan salah satu penyakit yang banyak dialami oleh masyarakat di Indonesia yang berhubungan erat dengan sanitasi lingkungan dan perilaku. Salah satu penyakit kecacingan adalah penyakit cacing usus yang penularannya melalui tanah atau disebut juga dengan Soil Transmitted Helminths (STH). Jenis cacing yang dimaksud adalah cacing gelang (Ascaris lumbricoides), cacing tambang (Ancylostoma duodenale dan Necator americanus), cacing cambuk (Trichuris trichiura) dan Strongyloides stercoralis [1]. Faktor-faktor yang berhubungan dengan penyakit ini erat hubungannya dengan hygiene dan sanitasi [2][3] [4], hasil bebrapa penelitian antara lain kebersihan diri seperti mencuci tangan dengan sabun, memakai alas kaki,kebiasaan memotong kuku merupakan cara yang terbaik dalam mencegah penularan dari kecacingan[5][6][7][8] [9] [10].Selain itu sanitasi merupakan salah satu faktor resiko terjadinya kecacinganAscaris lumbricoides seperti pemakaian jamban yang tidak layak akan menimbulkan pencemaran pada tanah dengan tinja di sekitar halaman rumah, ketersediaan tempat pembuangan sampah dan ketersediaan air bersih [1] [11]

Menurut WHO tahun 2016 [12] lebih dari 1,5 miliar orang atau 24\% dari populasi dunia mengalami kecacingan STH dan lebih dari 870 juta anak hidup di lingkungan yang penularannya sangat intensif dan membutuhkan pengobatan akibat parasit ini. Prevalensi kejadian kecacingan di Indonesia pada anak berkisar 2,7 - 60,7\% [13].Berdasarkan data dari Dinas Kesehatan Kota Pekanbaru tahun 2013 diketahui kecacingan pada anak sebanyak 446 orang.

Perhatian para peneliti terhadap kecacingan pada anak lebih banyak pada anak usia sekolah baik presentasi maupun faktor -faktor yang berhubungan dengannya dibandingkan pada anak usia dibawahnya, kemungkinan karena pada anak usia ini penularan lebih berisiko dan sebagai respondenpun anak usia ini sudah mampu memahami petanyaan sehingga memudahkan dalam penelitian. Padahal anak usia 1-5 tahun juga sangat berisiko untuk tertularnya penyakit ini. Pada usia ini anak sudah mulai beraktivitas seprti memasukkan jari ditangan, bermain ditanah dan lain-lain.Kecacingan berdampak buruk terhadap perkembangan kesehatan dan mental bahkan dapat menghambat tumbuh kembang anak, kecacatan dan kebutaanArimbi[14]. Peran orang tua dalam upaya pencegahan kecacingan pada anak usia 1-5 tahun sangat besar terutama ibu karena anak belum memahami tentang kebersihan diri. Ibu yang kurang menjaga kebersihan dirinya setelah beraktivitas kontak dengan tanah (misalanya berkebun, membersihkan halaman, memegang sayuran kotor dan lain-lain) maka anak yang dalam pengasuhannya akan dapat mengalami kecacingan. Misalnya ibu menyuapi anak makan yang sebelumnya tidak mencuci tangan menggunakan sabun. Penelitian pada anak balita di Surabya terdapat 9,8\% anak kecacingan[15], pada anak 1-4 tahun di Semarang 36\% kecacingan[16][17]Data dari Dinkes Kota Pekanbaru tahun 2013 Kecamtan Rumbai Pesisir diatas adalah untuk seluruh anak baik pra maupun usia sekolah. Belum diketahui presentasi kecacingan pada anak usia 1-5 tahun. Hasil survei di Kelurahan Geringging Kecamatan Rumbai pesisir tepatnya RW 07 bahwa terlihat anakanak bermain tanpa alas kaki dan sanitasi di daerah tersebut memungkinkan terjadinya kecacingan. Hasil wawancara pada staf Puskesmas Rumabi pesisir belum ada dilakukan penelitian 
tentang faktor-faktor yang berhubungan dengan kecacingan pada anak usia 1-5 tahun, sehingga peneliti merasa perlu dilakukan penelitian didaerah tersebut.

\section{Metode Penelitian}

Penelitian ini merupakan kuantitatif observasional dengan desain cross sectional, yang dilaksanakan di Rw 07 Kelurahan Geringging Kecamatan Rumbai Pesisir Pekanbaru tahun 2017. Populasi dalam penelitian adalah anak usia 1-5 tahun berjumlah 55 orang dengan jumlah sampel adalah seluruh populasi yaitu 55 orang. Variabel independen yang dikumpulkan adalah ,kebiasaan mencuci tangan, kebiasaan memakai alas kaki (pada anak),kebersihan kuku ibu dan anak, ketersediaan air bersih, ketersediaan jamban dan ketersediaan tempat sampah dan variabel dependen adalah kecacingan. Data yang dikumpulkan adalah data primer dari semua variabel independen dengan memberikan kuesioner pada ibu dari anak usia 1-5 tahun sebagai responden, data pemeriksaan kecacingan pada feses anak menggunakan mikroskop, analisis bivariat dilakukan dengan uji Chi-Square

\section{Hasil dan Pembahasan}

Hubungan variabel independen terhadap kejadian kecacingan dapat dilihat pada tabel 1 dibawah ini.

Tabel 1. Hubungan Beberapa Variabel IndependenTerhadap Kejadian Kecacingan Pada anaka Usia 1-5 Tahun di Kelurahan Geringging Kecamatan Rumbai Pesisir Pekanbaru

\begin{tabular}{|c|c|c|c|c|c|c|c|}
\hline \multirow{3}{*}{\begin{tabular}{|c|} 
Variabel \\
Independen dan \\
Kategori \\
\end{tabular}} & & Infek & acinn & & \multicolumn{2}{|c|}{ Jumlah } & \multirow{3}{*}{ P value } \\
\hline & \multicolumn{2}{|r|}{$\mathrm{Ya}$} & \multicolumn{2}{|c|}{ Tidak } & \multirow{2}{*}{$\mathrm{N}$} & \multirow{2}{*}{$(\%)$} & \\
\hline & $\mathrm{N}$ & $(\%)$ & $\mathrm{N}$ & $(\%)$ & & & \\
\hline \multicolumn{8}{|c|}{$\begin{array}{l}\text { Kebiasaan mencuci } \\
\text { tangan }\end{array}$} \\
\hline Tidak & 1 & $(3,3)$ & 18 & $(96,7)$ & 25 & (100) & \\
\hline \multicolumn{8}{|l|}{ Kebiasaan } \\
\hline \multicolumn{8}{|l|}{$\begin{array}{l}\text { menggunakan } \\
\text { kaki }\end{array}$} \\
\hline $\mathrm{Ya}$ & 2 & $(4,5)$ & 42 & $(95,5)$ & 44 & $(100)$ & 0,002 \\
\hline Tidak & 5 & $(45,5)$ & 6 & $(54,6)$ & 11 & (100) & \\
\hline \multicolumn{8}{|l|}{ Kebersihan kuku } \\
\hline Bersih & 2 & $(5,6)$ & 34 & $(94,4)$ & 36 & $(100)$ & 0,041 \\
\hline Kotor & 5 & $(26,3)$ & 14 & $(73,7)$ & 19 & $(100)$ & \\
\hline \multicolumn{8}{|l|}{$\begin{array}{l}\text { Ketersediaan } \\
\text { bersih }\end{array}$} \\
\hline $\mathrm{Ya}$ & 0 & $(0,0)$ & 45 & $(100)$ & 45 & (100) & 0,016 \\
\hline Tidak & 7 & $(70.0)$ & 3 & $(30,0)$ & 10 & $(100)$ & \\
\hline \multicolumn{8}{|l|}{ Ketersediaan jamban } \\
\hline Tersedia & 0 & $(0,0)$ & 44 & $(100)$ & 44 & $(100)$ & 0,024 \\
\hline Tidak Tersedia & 7 & $(63,6)$ & 4 & $(36,4)$ & 11 & $(100)$ & \\
\hline \multicolumn{8}{|l|}{ Ketersedaan tempat } \\
\hline Terseda & 0 & $(0.0)$ & 43 & $(100)$ & 43 & $(100)$ & 0,168 \\
\hline TidakTersedia & 7 & $(12,7)$ & 5 & $(87,3)$ & 12 & $(100)$ & \\
\hline
\end{tabular}


Berdasarkan tabel 1 terhadap 55 sampel feses pada anak usia $1-5$ tahun terdapat 7 anak $(12,7 \%)$ yang terinfeksi telur cacing . Dari 7 sampel yang positif tersebut, ditemukan 4 telur Ascaris lumbricoides (7,2\%), 2 telur Trichuris trichiura (3,6\%), dan 1 telur cacing tambang (1,8\%) Hasil tersebut menunjukkan bahwa rendahnya prilaku kebersihan diri dan sanitasi lingkungan ibu pada anak beresiko terhadap terjadinya infeksi telur cacing.

\section{Kebiasaan mencuci tangan}

Berdasarkan hasil penelitian menunjukkan bahwa ibu yang memiliki kebiasaan mencuci tangan terdapat 1 anaknya $(3,3 \%)$ terinfeksi telur cacing dan yang tidak terinfeksi telur cacing terdapat 29 anak $(96,7 \%)$, sedangkan ibu yang tidak memiliki kebiasaan mencuci tangan terdapat 6 anaknya (24\%) terinfeksi telur cacing dan yang tidak terinfeksi telur cacing terdapat 19 anak (76\%). Hal ini menunjukkan bahwa Ibu yang tidak memiliki kebiasaan mencuci tangan menggunakan sabun dan air mengalir dapat menularkan telur atau larva cacing pada saat menyuapkan makanan kepada anak, maka telur cacing yang ada pada tangan ibu masuk ke dalam mulut sehingga tertelan oleh anak.Hasil uji statistik chi square antara variabel kebiasaan mencuci tangan dengan infeksi telur cacing STH didapatkan nilai $p$-value 0,039, artinya ada hubungan antara kebiasaan ibu mencuci tangan dengan infeksi telur cacing STH. Hasil ini sesuai dengan penelitian Yudhastuti[15].

\section{Kebiasaan menggunakan alas kaki}

Berdasarkan tabel 1 menunjukkan bahwa 44 anak yang terbiasa menggunakan alas kaki terdapat 2 anak $(4,5 \%)$ yang terinfeksi telur cacing dan 42 anak $(95,5 \%)$ yang tidak terinfeksi telur cacing, sedangkan 11 anak yang tidak memiliki kebiasaan memakai alas kaki terdapat 5 anak $(45,5 \%)$ yang terinfeksi telur cacing dan 6 anak (54,5\%) yang tidak terinfeksi telur cacing..Hasil uji chi square antara kebiasaan memakai alas kaki dengan infeksi telur cacing menghasilkan nilai p-value sebesar 0,002, artinya ada hubungan antara kebiasaan anak memakai alas kaki dengan infeksi telur cacing..Anak yang tidak menggunakan alas kaki saat bermain di tanah akan memudahkan larva cacing tambang masuk melalui kulit kaki, karena salah satu cara penularan cacing tambang melalui per kutan atau penetrasi kulit yaitu apabila larva infektif yang bisa menembus melalui kulit[3] . Dalam penelitian ini ditemukan satu anak yang terinfeksi telur cacing tambang, tentunya hal ini disebabkan karena kebiasaan anak yang tidak memakai sandal atau alas kaki pada saat bermain di tanah. Untuk menghindari agar anak tidak tertular infeksi telur cacing saat bermain di tanah, sebaiknya orang tua lebih memperhatikan dan mengajarkan anaknya untuk selalu menggunakan alas kaki apabila bermain di tanah ataupun hendak keluar rumah. Penelitian tidak sejalan dengan penelitian Yudhastuti[15] dan Erdiani[16] yang menunjukkan tidak ada hubungan antara penggunaan alas kaki dengan kejadian kecacingan.

\section{Kebersihan kuku ibu dan anak}

Berdasarkan hasil penelitian menunjukkan bahwa ibu dan anak yang memiliki kebersihan kuku terdapat 2 anak (5,6\%) terinfeksi telur cacing dan 34 anak $(94,4 \%)$ lainnya tidak terinfeksi 
telur cacing. Sedangkan ibu dan anak yang tidak memiliki kebersihan kuku terdapat 5 anak (26,3\%) yang terinfeksi telur cacing dan 14 anak $(73,7 \%)$ anak tidak terinfeksi telur cacing. Kebiasaan anak-anak bermain tanah yang terkontaminasi telur cacing dapat menyebabkan tangan dan kuku anak menjadi kotor. Kuku yang kotor tersebut akan menjadi sarang bagi telur cacing, sehingga kebiasaan anak-anak yang menggigit kuku dan memasukkan jari ke dalam mulutnya akan mempermudah telur cacing untuk masuk ke dalam tubuh. Memelihara kuku pada anak sebaiknya kuku dipotong minimal seminggu sekali [18] Hasil uji chi square antara kebersihan kuku dengan infeksi telur cacing menghasilkan nilai $p$-value 0,041 , artinya ada hubungan antara kebersihan kuku ibu dan anak dengan infeksi telur cacing STH. Hasil ini tidak sesuai dengan penelitian Yudhastuti [15]dan Erdiani[16].ada pebedaan antara penelitian ini dengan sebelumnya yaitu kebersihan kuku yang diobservasi pada penelitian ini bukan saja pada anak tetapi juga kebersihan kuku ibu. Jadi kebersihan kuku ibu mempunyai peranan penting dengan terjadinya kecacingan pada anak.ibu yang menyuapi anaknya menggunakan tangan dimana kuku ibu dalam keadaan panjang dan kotor maka dapat menularkan kecacingan.

\section{Ketersediaan air bersih}

Dari tabel 1dapat dilihat bahwa anak yang rumahnya memiliki ketersediaan air bersih tidak ada yang terinfeksi telur cacing $(0.0 \%)$. Sedangkan anak yang rumahnya tidak memiliki ketersediaan air bersih 7 anak (70,0 \%) yang terinfeksi telur cacing dan 3 anak (30\%) anak tidak terinfeksi telur cacing. Meskipun keadaan ini menggambarkan bahwa kondisi penyediaan air bersih sebagian masyarakat sudah memenuhi syarat, namun dalam kenyataannya masih ada balita yang terkena penyakit cacingan. Hal ini dikarenakan masih ada kondisi air yang tidak memenuhi syarat kesehatan. syarat-syarat air yang sehat yaitu memenuhi persyaratan fisik (tidak berasa, berbau, dan tidak berwarna), persyaratan bakteriologis (untuk mengurangi terkontaminasinya mikroorganisme patogen)[19].Berdasarkan hasil uji statistik chi-square diperoleh nilai $P$ value 0,016, artinya pada variabel ketersediaan air bersih memiliki hubungan secara signifikan dengan kecacingan Soil Transmitted Helminth, hal ini sama dengan penelitian Yudhastuti[15].Salah satu penularan askariasis dapat terjadi melalui beberapa jalan, yaitu masuknya telur infektif ke dalam mulut bersama makanan atau minuman yang tercemar. Ketersediaan air bersih merupakan salah satu kebutuhan manusia untuk minum, masak, mandi, dan mencuci (bermacam-macam sayuran). Oleh karena itu untuk keperluan sehari-hari air harus mempunyai syarat kesehatan agar tidak menimbulkan suatu penyakit[20][19]

\section{Ketersediaan jamban}

Dari tabel 1 menunjukkan bahwa anak yang rumahnya memiliki ketersediaan jamban tidak ada yang terinfeksi telur cacing $(0,0 \%)$. Sedangkan anak yang rumahnya tidak memiliki ketersediaan jamban terdapat 7 anak $(63,6 \%)$ yang terinfeksi telur cacing dan 4 anak $(36,4 \%)$ tidak terinfeksi telur cacing. Kondisi jamban di RW 07 masih memprihatinkan, yaitu keadaan jamban yang kumuh, kurang tersedianya air bersih, kurang pencahayaan dan sering dihinggapi serangga terutama lalat. Kurangnya penyediaan jamban akan mempercepat penyebaran penyakit-penyakit yang ditularkan melalui tinja, diantaranya penyakit tifus, disentri, kolera dan kecacingan[19].Berdasarkan hasil uji statistik chi-square diperoleh nilai $P=0,024$, artinya pada 
variabel ketersediaan jamban memiliki hubungan secara signifikan dengan kecacinganSoil Transmitted Helminth. Hal ini sama dengan penelitian Yudhastuti[15]dan Altiara[21].

\section{Ketersediaan tempat sampah}

Dari tabel 1 menunjukkan bahwa anak yang rumahnya memiliki ketersediaan tempat sampah tidak ada yang terinfeksi telur cacing $(0,0 \%)$. Sedangkan anak yang rumahnya tidak memiliki ketersediaan tempat sampah terdapat 7 anak (12,7\%) yang terinfeksi telur cacing dan 4 anak $(87,3 \%)$ anak tidak terinfeksi telur cacing

Berdasarkan hasil uji statistik chi-square kondisi tempat sampah tidak berpengaruh signifikan, terlihat dari nilai $P=0,168$, artinya pada variabel ketersediaan tempat sampah tidak memiliki hubungan secara signifikan dengan kecacinganSoil Transmitted Helminth.penelitian ini sejalan denga penelitian Altira[21]

\section{Kesimpulan}

Persentase kecacingan anak usia 1-5 tahun yang sebesar 12,7\% dengan jenis cacing Ascaris lumbricoides 7,2\%, Trichuris trichiura 3,6\%, dan cacing tambang1,8\%.Variabel yang berhubungan dengan kejadian kecacingan adalah kebiasaan mencuci tanganibu, kebiasaan memakai alas kaki,kebersihan kuku ibu serta anak,ketersediaan air bersih dan ketersediaan jamban dengan kejadian kecacingan.Diharapkan kepada ibu agar meperhatikan kebersihan diri dan kebersihan anaknya agar terhindar dari kecacingan. Untk peneliti selajutnya dapat meniliti faktor lain yang berhubungan dengan kecacingan seperti karakteristik anak, pengetahuan dan pekerjaan orang tua

\section{Referensi}

[1] S. Sutanto, I., Ismid, I.S., Sjarifuddin, P.K., Sungkar, Buku Ajar Parasitologi Kedokteran, Keempat. Jakarta: FKUI, 2008.

[2] R. Safar, Parasitologi kedokteran Protizoa, helmintologi Entomologi. Bandung: CV Yrama widya, 2009.

[3] H. Widodo, Parasitologi Kedokteran. Yogyakarta: D-Medika, 2013.

[4] D. RI, "Keputusan Mentri Kesehatan Republik Indonesia N0. 24/MENKES/VI/2006 Pedoman Pengendalian Cacingan.” 2006.

[5] A. Mokodompit, A. Y. Ismanto, and F. Onibala, "Hubungan Tindakan Personal Hygiene Ibu Dengan Kjadian Diare Pada Balita Di Puskesmas Bilalang Kota Kotamobagu," J. KEPERAWATAN, vol. 3, no. 2, 2015.

[6] S. Kola, M. Racheal, and A. Elizabeth, "Soil-transmitted helminth infections among school children in rural communities of Moro Local Government Area, Kwara State, Nigeria," African J. Microbiol. Res., vol. 7, no. 45, pp. 5148-5153, 2013.

[7] B. T. Ratag, F. R. R. Maramis, and K. Dareda, "Hubungan Antara Higiene Perorangan Dengan Infestasi Cacing Usus Pada Siswa Sekolah Dasar Negeri 119 Manado,” Bul. IDI Manad. Hal, pp. 19-25, 2011.

[8] K. Deribe et al., "The burden of neglected tropical diseases in Ethiopia , and opportunities for integrated control and elimination," Parasit. Vectors, vol. 5, no. 1, p. 1, 2012.

[9] S. Debalke, A. Worku, N. Jahur, and Z. Mekonnen, "Soil transmitted helminths and associated factors among schoolchildren in government and private primary school in Jimma Town, Southwest Ethiopia," Ethiop. J. Health Sci., vol. 23, no. 3, pp. 237-244, 2013.

[10] S. Kartini, "Kejadian Kecacingan pada Siswa Sekolah Dasar Negeri Kecamatan Rumbai Pesisir Pekanbar," J. Kesehat. Komunitas, vol. 3, no. 2, pp. 53-58, 2016.

[11] J. Fitri, Z. Saam, and M. Y. Hamidy, "Analisis faktor-faktor risiko infeksi kecacingan murid sekolah dasar di Kecamatan Angkola Timur Kabupaten Tapanuli Selatan tahun 2012," J. Ilmu Lingkung., vol. 6, no. 2, 2013.

[12] WHO, "Soil-Transmitted Helminth Infection," 2016. 
[13] Depkes, Profil Kesehatan Indonesia. Jakarta, 2009.

[14] H. Arimbi, Tumbuh Kembang, Staus Gizi dan Imunisasi Pada Balita. Jakarta: Nuha Medika, 2010.

[15] R. Yudhastuti and M. F. D. Lusno, "Kebersihan Diri dan Sanitasi Rumah pada Anak Balita dengan Kecacingan Personal Hygiene and House Sanitation among Children Under Five Years Old with Helminthiasis," pp. 173-178, 2010.

[16] S. Endriani, Mifbakhudin, "Beberapa Faktor Yang Berhubungan Dengan Kejadian Kecacingan Pada Anak Usia1-4 Tahun," J Kesy Mash Indones, pp. 22-35, 2010.

[17] A. Tri, R. Amaliah, and D. Indo-, "Distribusi Spasial Kasus Kecacingan ( Ascaris lumbricoides ) Terhadap Personal Higiene Anak Balita di Pulau Kodingareng Kecamatan Ujung Tanah Kota Makassar Tahun 2016," 2016.

[18] A. Murtie, All About Kesehatan Anak. Jogjakarta: Idea Publishing, 2014.

[19] N. Soekidjo, Kesehatan Masyarakat Ilmu dan Seni. Jakarta: Rineka Cipta, 2007.

[20] Sudarto, Buku Ajar Helmintologi Kedokteran. Suarabaya: AUAP, 2011.

[21] S. Altiara, "Hubungan Sanitasi Lingkungan Rumah dengan Kejadian Cacingan Pada Balita di RW 03 Kelurahan Panggng Kota Tegal,” 2010. 